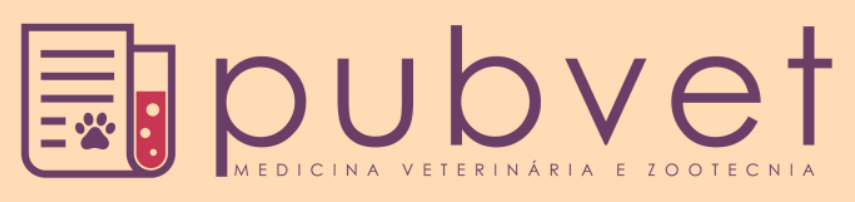

https://doi.org/10.22256/pubvet.v12n5a90.1-4

\title{
Avaliação morfológica do fígado de um exemplar de veado catingueiro (Mazama gouazoubira, Fischer, 1814)
}

\author{
Bruna Carolina Ulsenheimer ${ }^{\ominus 1}$, Eduardo dos Santos Marques ${ }^{\bullet}$, Orestes Moraes \\ Cabeleira ${ }^{\ominus}$, Gabriele Maria Callegaro Serafini ${ }^{\bullet}{ }^{2 *}$, Cristiane Elise Teichmann ${ }^{\bullet} 2$ \\ ${ }^{1}$ Acadêmico(a) do curso de Medicina Veterinária da Universidade Regional do Noroeste do Estado do Rio Grande do Sul (UNIJUÍ), \\ Departamento de Estudos Agrários, Íjuí-RS, Brasil. \\ ${ }^{2}$ Professora do curso de Medicina Veterinária, UNIJUÍ, Departamento de Estudos Agrários. Ijuí-RS, Brasil. \\ * Autor para correspondência, E-mail: gabrieleserafini@yahoo.com.br
}

\begin{abstract}
RESUMO: A fim de maiores esclarecimentos sobre a anatomia dos cervídeos, objetiva-se com esse trabalho, descrever a morfologia do fígado de um exemplar de veado Catingueiro. O mesmo foi avaliado no Laboratório de Anatomia Veterinária da Universidade Regional do Noroeste do Estado do Rio Grande do Sul (UNIJUI), o qual apresentou um formato retangular, com identificação dos lobos direito, esquerdo, quadrado e caudado com processo caudado e um discreto processo papilar, além de ausência de vesícula biliar.
\end{abstract}

Palavras-chave: anatomia, animal selvagem, órgão, ruminante

\section{Morphological evaluation of the liver of an example of deer Mazama gouazoubira, (Fischer, 1814)}

\begin{abstract}
In order to further clarify the anatomy of deer, we aim to describe the morphology of the liver of a specimen of deer Mazama gouazoubira. The same was evaluated in the Laboratory of Veterinary Anatomy of the Universidade Regional do Noroeste do Estado do Rio Grande do Sul (UNIJUI), which presented a rectangular shape, with identification of the right, left, square and caudate lobes with caudate process and a discreet papillary process, besides absence of gallbladder.
\end{abstract}

Keywords: anatomy, wild animal, organ, ruminant

\section{La evaluación morfológica del hígado de un ejemplar de venado Mazama gouazoubira (Fischer, 1814)}

RESUMEN. A fin de esclarecer la anatomía de los cervídeos, con este trabajo se objetivó describir la morfología de un ejemplar de venado Mazama gouazoubira. Dicho animal fue analizado en el Laboratorio de Anatomía Veterinaria de la Universidade do Noroeste do Estado do Rio Grande do Sul (UNIJUI), el cual presentó un formato rectangular, con identificación de lóbulos derecho, izquierdo, cuadrado, caudado con proceso caudado y un discreto proceso papilar, además de ausencia de vesícula biliar.

Palabras clave: anatomía, animal salvaje, órgano, rumiante

\section{Introdução}

O fígado em mamíferos domésticos representa a maior glândula do corpo e desempenha funções essenciais à vida, atua no metabolismo de carboidratos, proteínas e gorduras, possui ação desintoxicante, contribui para o armazenamento de glicose sob a forma de glicogênio e elimina diversas substâncias, fatores que conferem a este órgão uma grande importância (Dyce et al., 2004, 
Cunningham, 2011). Este fato leva muitos pesquisadores a estudar os múltiplos aspectos morfológicos desta glândula nas diferentes espécies, permitindo estabelecer uma anatomia comparativa (Ferreira et al., 2011, Schwarz, 2012).

O veado catingueiro Mazama gouazoubira (Fischer, 1814) pertence a uma das oito espécies de ruminantes da família Cervidae que vivem no Brasil. Abundante e amplamente distribuído pela América Central e América do Sul, pode apresentar-se em florestas, matas ciliares de galeria, até cerrados abertos, campos e capoeiras (Duarte et al., 2012).

De maneira geral, os cervídeos neotropicais ainda são pouco estudados, sejam em relação à sua taxonomia ou quanto às demais características. Essa escassez é gerada pela dificuldade de acesso aos animais, que vivem em sua maioria em florestas e possuem hábitos crepusculares (Cubas et al., 2014). No entanto, observa-se que são cada vez maiores os casos de atendimento desses animais por médicos veterinários. Estes atendimentos, em geral, se dão em virtude de acidentes causados pela proximidade destes animais aos centros urbanos. De acordo com Tiepolo \& Tomas (2006) os atropelamentos em estradas, seguido dos ataques por cães domésticos estão entre as maiores causas de atendimentos a veados catingueiros.

Diante do exposto e da necessidade de maiores informações acerca das características anatômicas dos cervídeos, o objetivo deste trabalho foi descrever a morfologia do fígado de um exemplar de veado catingueiro recebido pelo Laboratório de Zoologia e Ictiologia e avaliado no Laboratório de Anatomia Veterinária da UNIJUI.

\section{Material e Métodos}

Um veado macho catingueiro (Mazama gouazoubira) com, aproximadamente, um ano de idade, foi levado ao campus da Universidade Regional do Noroeste do Estado do Rio Grande do Sul já sem vida devido a um atropelamento. O mesmo foi resgatado pela Vigilância Ambiental de Ijuí e doado para estudos de anatomia e realização de técnicas de taxidermia ao Laboratório de Zoologia e Ictiologia da UNIJUI. Após as adequações do cadáver para a realização da técnica de taxidermia, as vísceras foram encaminhadas para o Laboratório de Anatomia Veterinária do curso de Medicina Veterinária, onde foram fixadas e armazenadas em
Formaldeído 10\% para conservação do tecido para posterior estudo das estruturas anatômicas.

Para o estudo macroscópico do fígado do veado catingueiro, observou-se a morfologia deste órgão mediante dissecação e inspeção visual. $\mathrm{O}$ fígado foi separado cuidadosamente do restante das vísceras abdominais, preservando a integridade de seu parênquima e ligamentos. Em seguida a peça foi lavada em água corrente a fim de retirar o excesso do conservante, procedendose as seguintes observações: forma, medida longitudinal e transversal, efetuadas com o auxílio de fita métrica, bem como a verificação da lobação desta glândula. Para documentação foram realizadas fotografias. $\mathrm{Na}$ sequência essas fotografias foram analisadas para melhorar visualizar o estado do animal.

\section{Resultados e Discussão}

$\mathrm{O}$ veado-catingueiro é uma espécie de porte pequeno, pesa em média $18 \mathrm{~kg}$, altura média de 50 $\mathrm{cm}$ na cernelha. Sua coloração pode variar do cinza escuro ao marrom avermelhado, podendo chegar até mais claro como o baio. A região ventral é baia, com áreas brancas na parte inferior da cauda e na face interna da orelha. As regiões submandibulares e perioftálmicas são mais claras, mas dificilmente chegam a ser brancas. A maioria dos indivíduos tem uma pinta branca acima dos olhos, que é inexistente em outras espécies de veados (Cubas et al., 2014). Tais atributos foram verificados no Laboratório de Zoologia e Ictiologia para identificação da espécie.

Nas espécies domésticas, o fígado apresenta duas superfícies: a superfície diafragmática que se situa contra a concavidade do diafragma e é convexa em forma; e a superfície visceral que é caudal e situa-se contra vários órgãos abdominais, dando seus nomes a depressões na superfície do fígado. Apresenta também uma grande fissura onde se aloja a veia porta. Neste local penetram a veia porta, artéria hepática, nervos e linfáticos e sai o ducto biliar (Reece, 2008, Dyce et al., 2004).

$\mathrm{O}$ tamanho relativo do fígado e seu padrão de lobação variam entre as espécies domésticas. $\mathrm{Na}$ maioria são descritos quatro lobos que são: lobo direito, lobo esquerdo, lobo quadrado e lobo caudado. Adicionalmente, cada lobo, exceto o quadrado pode estar subdividido em sub-lobos (König \& Liebich, 2011). Essas características morfológicas foram levadas em consideração para fazer a comparação do presente exemplar com as espécies domésticas em geral. Diante disso, 
observaram-se algumas particularidades dispostas a seguir.

A avaliação da morfologia externa do fígado do veado catingueiro permitiu identificar, na superfície externa deste órgão, a borda direita, esquerda, dorsal e ventral. Seu comprimento foi de $17 \mathrm{~cm}$ e sua altura de $10 \mathrm{~cm}$, conferindo-lhe um formato retangular. A face parietal era mais convexa, provavelmente por se adaptar à cúpula diafragmática, e a face visceral mais plana, com impressões dos órgãos vizinhos. Por apresentar este formato, o fígado deste ruminante selvagem provavelmente localiza-se na porção cranial da cavidade abdominal, e seu parênquima coloca-se, em grande parte, à direita do plano mediano deslocado pelo tamanho do rúmen, como descrito por Dyce et al. (2004) para os pequenos ruminantes domésticos.

Foi observado que o parênquima se relacionava dorsalmente com a veia cava caudal, vaso que imprime, na sua borda dorsal, um sulco percorrendo quase todo o seu comprimento. Esta descrição não se afasta das referidas por König \& Liebich (2011) para os bovinos, caprinos e ovinos.

O fígado não apresentou vesícula biliar, semelhante às descrições anatômicas descritas por (Reece (2008), Dyce et al. (2004)) para equinos, sendo a bile lançada diretamente do fígado para o intestino delgado. Observação também descrita por Miglino et al. (1995) em um estudo onde foram avaliadas as vias bilíferas de três espécies de cervídeos distintas da que foi analisada no presente caso, o que nos permite afirmar que esta estrutura, assim como o ducto cístico, não são identificados neste grupo de animais, embora sejam constantes nos ruminantes domésticos.

Em relação à definição da lobação do órgão foi possível identificar à esquerda da incisura umbilical, o lobo esquerdo, de espessura mais delgada e à direita desta incisura, uma massa parenquimatosa mais espessa que corresponde ao lobo quadrado e ao lobo direito. Sobrepondo dorsalmente esta porção do órgão, encontrou-se o lobo caudado, apresentando um discreto processo papilar contínuo com o processo caudado, sobrepondo o espaço porta (Figura 1). O processo caudado, juntamente com o lobo direito, delimita a fossa renal, configurando a relação deste órgão com o rim direito. Estas alusões são semelhantes às descrições morfológicas para pequenos ruminantes referidas por König \& Liebich (2011) e Dyce et al. (2004).

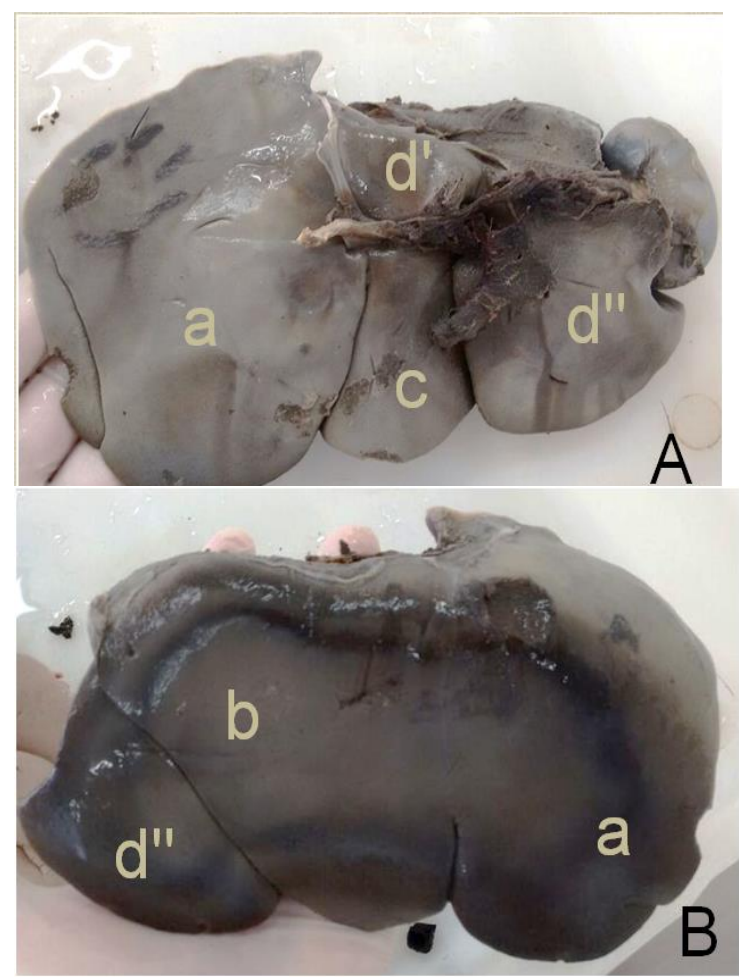

Figura 1. Fígado de um exemplar de veado catingueiro. Face visceral mais plana (A). Face parietal mais convexa (B). Lobo esquerdo (a), lobo direito (b), lobo quadrado (c) e o lobo caudado, com um discreto processo papilar (d') contínuo com o processo caudado (d'").

\section{Conclusão}

O fígado do cervídeo da espécie Mazama gouazoubira (Fischer, 1814), avaliado no Laboratório de Anatomia Veterinária da UNIJUI, apresentou $17 \mathrm{~cm}$ de comprimento e $10 \mathrm{~cm}$ de altura, conferindo-lhe um formato retangular. As margens evidenciadas foram lateral direita, lateral esquerda, dorsal e ventral. Foram identificados os lobos direito, esquerdo, quadrado e caudado com processo caudado e um discreto processo papilar. Por fim, confirmou-se a ausência de vesícula biliar como já evidenciado por outros autores para cervídeos.

\section{Referências Bibliográficas}

Cubas, Z. S., Silva, J. C. R. \& Dias, J. L. C. 2014. Tratado de animais selvagens-medicina veterinária. Editora Roca.

Cunningham, J. 2011. Tratado de fisiologia veterinária. Guanabara Koogan, Rio de Janeiro.

Duarte, J. M. B., Piovezan, U., Zanetti, E. S. \& RamoS, H. G. C. 2012. Espécies de cervídeos brasileiros não ameaçadas de extinção. In: Duarte, J. M. B. \& Reis, M. L. (eds.) Plano de Ação Nacional para a Conservação dos 
Cervídeos Ameaçados de Extinção. Instituto Chico Mendes de Conservação da Biodiversidade, Brasília, Brasil.

Dyce, K. M., Wensing, C. J. G. \& Sack, W. O. 2004. Tratado de anatomia veterinária. Elsevier Brasil, São Paulo.

Ferreira, A. O., Morini, A. C., Favaron, P. O., Passos, C. C., Campos, D. B., Miglino, M. A. \& Guerra, R. R. 2011. Avaliação morfológica das membranas fetais e da placenta de Mazama gouazoubira (veado-catingueiro) de vida livre no terço inicial da gestação. Pesquisa Veterinária Brasileira, 31, 631-635.

König, H. E. \& Liebich, H.-G. 2011. Anatomia dos Animais Domésticos. Artmed Editora.

Miglino, M. A., Souza, W. M. \& Didio, L. J. A. 1995. Sistema excretor do fígado de veados (Manzana americana, Blastocerus bezoarticus e Manzana simplicicornis). II. Sistematização do ramus principalis sinester. Brazilian Journal of Veterinary Research and Animal Science, 32, 219-223.
Reece, W. O. 2008. Anatomia funcional $e$ fisiologia dos animais domésticos. Editora Roca, São Paulo.

Schwarz, T. 2012. Fígado e Vesícula Biliar. In: O'Brien, R. \& Barr, F. (eds.) Manual de Diagnóstico por Imagem Abdominal de Cães e Gatos. Roca, São Paulo.

Tiepolo, L. M. \& Tomas, W. M. 2006. Ordem Artiodactyla. In: N.R., R., A.L., P., Pedro, W. A. \& Lima, I. P. (eds.) Mamíferos do Brasil. Universidade Estadual de Londrina, Londrina, Paraná, Brasil.

Article History:

Received 23 February 2018

Accepted 11 April 2018

Available online 3 May 2018

License information: This is an open-access article distributed under the terms of the Creative Commons Attribution License 4.0, which permits unrestricted use, distribution, and reproduction in any medium, provided the original work is properly cited 